\title{
Association between the c. 2495 A $>$ G ATP7B Polymorphism and Sporadic Alzheimer's Disease
}

\section{Serena Bucossi, ${ }^{1,2}$ Stefania Mariani, ${ }^{1,2}$ Mariacarla Ventriglia,, ${ }^{1,2}$ Renato Polimanti, ${ }^{3}$ Massimo Gennarelli, ${ }^{4}$ Cristian Bonvicini, ${ }^{4}$ Patrizio Pasqualetti, ${ }^{2}$ Federica Scrascia, ${ }^{1}$ Simone Migliore, ${ }^{2}$ Fabrizio Vernieri, ${ }^{1}$ Paolo M. Rossini, ${ }^{1,5}$ and Rosanna Squitti ${ }^{1,2}$}

\author{
${ }^{1}$ Department of Neurology, Campus Bio-Medico University of Rome, 00128 Rome, Italy \\ ${ }^{2}$ Department of Neuroscience, AFaR-Fatebenefratelli Hospital, 00186 Rome, Italy \\ ${ }^{3}$ Department of Biology, Tor Vergata University of Rome, 00173 Rome, Italy \\ ${ }^{4}$ Genetics Unit, IRCCS San Giovanni di Dio-Fatebenefratelli, 25125 Brescia, Italy \\ ${ }^{5}$ Department of Imaging, San Raffaele Cassino, 03043 Cassino FR, Italy
}

Correspondence should be addressed to Serena Bucossi, s.bucossi@unicampus.it

Received 30 December 2010; Accepted 1 April 2011

Academic Editor: D. Larry Sparks

Copyright (C) 2011 Serena Bucossi et al. This is an open access article distributed under the Creative Commons Attribution License, which permits unrestricted use, distribution, and reproduction in any medium, provided the original work is properly cited.

\begin{abstract}
Nonceruloplasmin-bound copper ("free") is reported to be elevated in Alzheimer's disease (AD). In Wilson's disease (WD) CuATPase 7B protein tightly controls free copper body levels. To explore whether the ATP7B gene harbours susceptibility loci for AD, we screened $180 \mathrm{AD}$ chromosomes for sequence changes in exons 2, 5, 8, 10, 14, and 16, where most of the Mediterranean WDcausing mutations lie. No WD mutation, but sequence changes corresponding to c.1216 T $>$ G Single-Nucleotide Polymorphism (SNP) and c.2495 A>G SNP were found. Thereafter, we genotyped $190 \mathrm{AD}$ patients and 164 controls for these SNPs frequencies estimation. Logistic regression analyses revealed either a trend for the c.1216 SNP $(P=.074)$ or a higher frequency for c.2495 SNP of the GG genotype in patients, increasing the probability of AD by $74 \%(P=.028)$. Presence of the GG genotype in ATP7B c.2495 could account for copper dysfunction in $\mathrm{AD}$ which has been shown to raise the probability of the disease.
\end{abstract}

\section{Introduction}

There is a general agreement on the existence of a link between Alzheimer's disease (AD) and oxidative stress phenomena triggered by transition metals $[1,2]$. The existence of systemic copper dysfunctions in $\mathrm{AD}$ has been a controversial issue for many years. In fact, many studies have reported an increase of circulating copper in $\mathrm{AD}$ patients with respect to healthy controls [3-13], many others no variation [1423], and two very recent studies even a decrease of plasma [24] and serum [25] copper in AD patients. Recently, to gain an objective evaluation to the question whether systemic copper variations are associated to $\mathrm{AD}$ a metaanalysis of all the studies carried out on serum/plasma copper in AD and healthy cohorts between 1983 and 2010 was run [26]. This analysis demonstrated that $\mathrm{AD}$ patients have higher levels of serum $\mathrm{Cu}$ than healthy controls. Even though moderate, the assessed copper increase was sufficient to unambiguously distinguish $\mathrm{AD}$ patients from healthy controls.

Abnormalities in serum copper not bound to ceruloplasmin ("free" copper [27]) can be advocated as an explanatory variable of copper disturbances in $\mathrm{AD}[26,28]$, as several research groups recently confirmed $[3,25,29,30]$. Normally, most human serum copper binds tightly to ceruloplasmin [27]. The remaining copper, that is free copper, is distributed and exchanged among albumin, alpha 2 macroglobulin, and low-molecular-weight compounds such as peptides and amino acids (e.g., histidine [31]. A key difference between the two pools lies in the fact that the low-molecular-weight compounds allow free copper to easily cross the BloodBrain Barrier (BBB) [32, 33]. A recent study confirmed the evidence that the copper transport into the brain is mainly achieved through the BBB as free copper ion, and the bloodcerebrospinal fluid barrier may serve as a main regulatory site of copper in the cerebrospinal fluid (CSF) [34]. 
Wilson's disease is the paradigmatic example of copper toxicosis or accumulation, in which large amounts of free copper enter the brain and cause cognitive impairment $[35,36]$, abnormal glial cells and degenerated ganglion cells in cerebral cortex, putamen, and dentate nucleuses $[35,36]$. In WD, free copper levels are disproportionately high due to defects in the ATPase 7B (WD protein) and represent most of the circulating copper. Systemic copper abnormalities in $\mathrm{AD}$ resemble those observed in $\mathrm{WD}$, though they are very much less severe $[10,37]$. Moreover, free copper correlates with the typical deficits $[9,38-40]$ and markers of AD, namely, CSF Amyloid Beta $(\mathrm{A} \beta)$ and Tau proteins [9], as well as an unfavourable prognosis of the disease [40], and tend to predict the annual worsening in Minimental State Examination (MMSE) $[10,41]$. WD is an autosomal recessive genetic disorder due to mutations in the ATP7B gene (WD gene), and the rate of occurrence of a single abnormal copy is 1 in 90 people [36]. Based on this, we initiated a hypothesis-driven candidate gene project to determine whether the WD ATP7B gene harbours susceptibility loci for late-onset $\mathrm{AD}[42,43]$. In particular, in the study presented, we explored the hypothesis that ATP7B sequence changes in exon 2, 5, 8, 10,14, and 16-where most of the Mediterranean WD-causing mutations lie-have a higher frequency in a group of patients affected by mild or moderate $\mathrm{AD}$ compared to a group of healthy individuals.

\section{Materials and Methods}

190 patients with $\mathrm{AD}$ and 164 elderly controls were recruited by two specialized dementia care centres: the Department of Neuroscience, Fatebenefratelli Hospital, Isola Tiberina, in Rome, and the Department of Neurology, Campus BioMedico University, Rome, Italy, using a common standardized clinical protocol [10].

The AD patients sample consisted of individuals with a diagnosis of probable $\mathrm{AD}$ according to NINCDS-ADRDA criteria $[44,45]$ and an MMSE score of 25 or less [41]. All AD patients underwent general medical, neurologic, and psychiatric assessments. Neuroimaging diagnostic procedures (magnetic resonance imaging or computed tomography) and complete laboratory analyses were performed to exclude other causes of progressive or reversible dementia. The control sample consisted of healthy volunteers with no clinical evidence of neurological and psychiatric disease. Criteria for exclusion of both patients and controls were conditions known to affect copper metabolism and biological variables of oxidative stress (e.g., diabetes mellitus, inflammatory diseases, recent history of heart or respiratory failure, chronic liver or renal failure, malignant tumors, and a recent history of alcohol abuse).

Among the study populations, $28 \mathrm{AD}$ cases and 41 controls were not analyzed for c.1216 T > G and 10 cases and 13 controls for $\mathrm{c} .2495 \mathrm{~A}>\mathrm{G}$ because during the analyses it was not possible to assess the genotype (insufficient DNA/blood sample, sequence analysis failure).

The study was approved by the local IRB, and all participants or legal guardians signed an informed consent.
2.1. SNPs Genotyping. We collected approximately $10 \mathrm{~mL}$ of peripheral blood samples from study participants. Genomic DNA from fresh whole blood was prepared using the conventional method for DNA isolation (QLAamp DNA Blood Midi kit).

Polymerase chain reaction (PCR) was performed to amplify the exons and flanking regions of the ATP7B gene. DNA amplification was carried out in a total volume of $25 \mu \mathrm{L}$ containing $50-100 \mathrm{ng}$ of genomic DNA, 10 pmol of each primer, $0.4 \mathrm{mM}$ of dNTPs, $3 \mathrm{mM} \mathrm{MgCl}_{2}$, and 1 unit of Taq polymerase (Taq Gold, Applied Biosystems) in a thermocycler (2720 Thermal Cycler Applied Biosystem). The conditions were denaturation at $95^{\circ} \mathrm{C}$ for $30 \mathrm{~s}, 30 \mathrm{~s}$ of appropriate annealing temperature (varying between $53^{\circ} \mathrm{C}-$ $58^{\circ} \mathrm{C}$ ), and $30 \mathrm{~s}$ of extension temperature at $72^{\circ} \mathrm{C}$ for 30 cycles with $5 \mathrm{~min}$ at $72^{\circ} \mathrm{C}$ final extension. Primers, sequences and annealing temperatures are reported in Table 1.

The PCR products that were free of contaminating bands due to nonspecific amplification were column-purified using Nucleo Spin Extract II (Macherey-Nagel). Sequencing PCR reaction was performed in a total volume of $20 \mu \mathrm{L}$ containing $2 \mu \mathrm{L}$ Terminator Ready Reaction mix (Applied Biosystems), 3.2 pmol primers, $3 \mu \mathrm{L}$ Dilution Buffer, 6 ng purified PCR product.

Bidirectional sequencing of exons 2, 5, 8, 10, 14, and 16 of the ATP7B gene was performed using an ABI prism 310 DNA analyzer (Applied Biosystems) with dye-termination chemistry.

Nucleotide changes were detected by comparing the sequence obtained in the chromatogram with the normal gene sequence [NG_008806.1; Homo sapiens ATPase, $\mathrm{Cu}^{++}$ transporting, beta polypeptide (ATP7B) on chromosome 13] using SeqScape software version 2.5 (Applied Biosystems).

PCR-restriction fragment length polymorphism (RFLP) assay was applied for detection of c.1216 T>G (rs1801243) ATP7B SNP in AD and healthy controls (Figure 1). PCRRFLP reaction was the same as the one reported above using specific oligonucleotide primers (Table 1 ). The $T>G$ transition at the exon 2 creates an MspAlI (Promega) restriction-endonuclease recognition site. The $584 \mathrm{bp}$ PCR product was digested with MspA1I only if the substitution was present. MspA1I reactions were performed at $37^{\circ} \mathrm{C}$ for $2 \mathrm{~h} 30 \mathrm{~min}$. All restriction products were analyzed on a $1.5 \%$ agarose gel by electrophoresis and visualized by staining the gel using ethidium bromide. Homozygous alleles of the TT genotype appeared as a $584 \mathrm{bp}$ DNA band on the gel, and homozygous alleles of the GG genotype appeared as a $375 \mathrm{bp}$ and an $209 \mathrm{bp}$ DNA band. Heterozygote alleles displayed a combination of the bands (584bp, $375 \mathrm{bp}$ and $209 \mathrm{bp}$ ). Direct DNA bidirectional sequencing was performed for $15 \%$ of the PCR products, which were randomly selected and analyzed to confirm the genotypes.

Detection of c.2495 A>G (rs1061472) ATP7B polymorphism was performed by direct bidirectional sequencing of exon 10.

Bidirectional sequencing of exon 10 was performed using an ABI prism 310 DNA analyzer (Applied Biosystem, Foster City CA) with dye-termination chemistry. PCR reaction was 
TABLe 1: Oligonucleotides sequences.

\begin{tabular}{|c|c|c|c|c|}
\hline & Primer forward for sequencing & Primer reverse for sequencing & $\begin{array}{l}\text { Annealing } \\
\text { temperature }\end{array}$ & $\begin{array}{l}\text { PCR } \\
\text { product }\end{array}$ \\
\hline Exon $2 \mathrm{a}$ & $5^{\prime}$ AGAGGCCGTCATCACTTATC $3^{\prime}$ & $5^{\prime}$ CAATGGCAATCAGAGTGGTA $3^{\prime}$ & $57^{\circ} \mathrm{C}$ & $255 \mathrm{bp}$ \\
\hline Exon $2 b$ & $5^{\prime}$ AGCTCCTAGGGGTTCAAAGT $3^{\prime}$ & $5^{\prime}$ CAAGGAAAGTTTGCAGGATT $3^{\prime}$ & $57^{\circ} \mathrm{C}$ & $584 \mathrm{bp}$ \\
\hline Exon 5 & $5^{\prime}$ TTTCACAGGCTTTCCTTGAT 3' & $5^{\prime}$ ATTTCCATGGGAAAAGTTGA $3^{\prime}$ & $53^{\circ} \mathrm{C}$ & $336 \mathrm{bp}$ \\
\hline Exon 8 & $5^{\prime}$ CGACTGTGCACAAAGCTAGA 3' & $5^{\prime}$ CATGGTGTTCAGAGGAAGTG $3^{\prime}$ & $54^{\circ} \mathrm{C}$ & $386 \mathrm{bp}$ \\
\hline Exon 10 & $5^{\prime}$ CAGCTGGCCTAGAACCTGAC 3' & $5^{\prime}$ TATCCTCCTGAGGGAACAT $3{ }^{\prime}$ & $53^{\circ} \mathrm{C}$ & $234 \mathrm{bp}$ \\
\hline Exon 14 & $5^{\prime}$ CTGTGCAGGTGTCTTGTTTC 3' & $5^{\prime}$ TTTTCCAGACCACACAGAGA $3^{\prime}$ & $57^{\circ} \mathrm{C}$ & $407 \mathrm{bp}$ \\
\hline \multirow[t]{2}{*}{ Exon 16} & 5' TGTCCTAAAGGATGCTGTCA 3' & $5^{\prime}$ GGAAAACAGGCCTGAAATTA $3^{\prime}$ & $55^{\circ} \mathrm{C}$ & $451 \mathrm{bp}$ \\
\hline & Primer forward for allele-specific PCR & Primer reverse for allele-specific PCR & & \\
\hline Exon 10 & 5' CAGCTGGCCTAGAACCTGACCC 3' & $\begin{array}{c}5^{\prime} \text { GAAACTTTCCCCCAGGGACCACCT } 3^{\prime} \\
5^{\prime} \text { ACTTTCCCCCAGGGACCACCC } 3^{\prime}\end{array}$ & $63^{\circ} \mathrm{C}$ & $141 \mathrm{bp}$ \\
\hline Beta actin & $5^{\prime}$ GTCACATCCAGGGTCCTCAC $3^{\prime}$ & 5' CACCTTCACCGTTCCAGTTT $3{ }^{\prime}$ & $65^{\circ} \mathrm{C}$ & $350 \mathrm{bp}$ \\
\hline
\end{tabular}

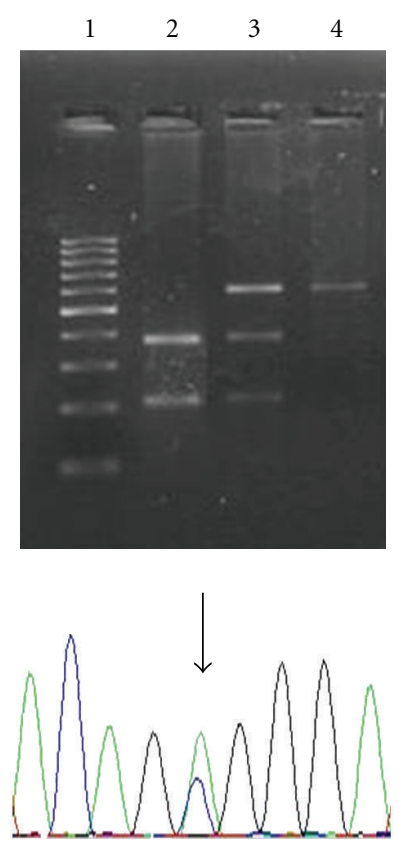

(a)

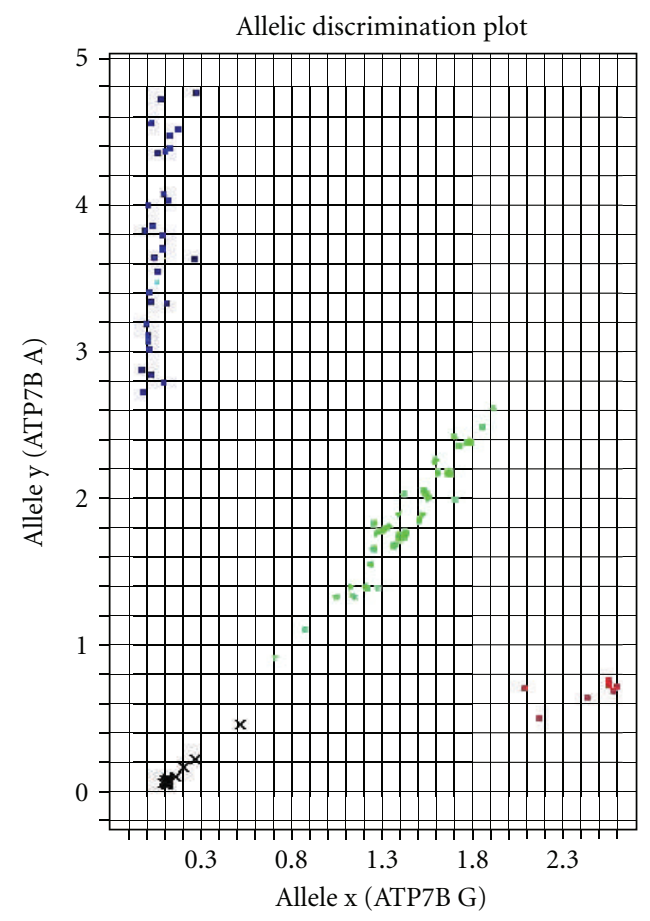

(b)

FIGURE 1: Analytical procedures for ATP7B SNPs detection. (a) PCR-restriction fragment length polymorphism (RFLP) assay for detection of c.1216 T>G SNP. Lane 1: PCR 100 bp low ladder. Lane 2: GG genotype (375 bp and 209 bp RFLP). Lane 3: TG genotype (584 bp, 375 bp and $209 \mathrm{bp}$ RFLP). Lane 4 : TT genotype (584 bp RFLP). In the electropherogram the arrow indicates the TG genotype. (b) TaqMan allelic discrimination assays for detection of c.2495 A>G SNP. Blue: AA genotype. Green: TG genotype. Red: GG genotype; x: undetermined.

the same as the one reported above. Oligonucleotides are detailed in Table 1.

Genotyping of SNPs rs1061472 was achieved by the TaqMan allelic discrimination assays from Applied Biosystems Inc. (Foster City CA) (Figure 1 ). The predesigned SNPs genotyping assay ID is ID C_1919004_30 (Applied Biosystems). The total reaction volume per well was $20 \mu \mathrm{L}$, including 5 ng genomic DNA, $1 \mu \mathrm{L}$ TaqMan SNP genotyping assay (containing two PCR primers and two dye (VIC or FAM)-labelled TaqMan MGB probes) and $10 \mu \mathrm{L}$ TaqMan
Universal PCR Master Mix (Applied Biosystems), according to the manufacturer's manual.

PCR was performed at $95^{\circ} \mathrm{C}$ for $10 \mathrm{~min}$ and 40 cycles at $95^{\circ} \mathrm{C}$ for $15 \mathrm{~s}$ and $60^{\circ} \mathrm{C}$ for $1 \mathrm{~min}$. The samples were amplified, read, and analyzed using the ABI Prism 7900HT Sequence Detection System and ABI Prism SDS 2.4 software. Two blank controls in each 96-well plate were used for the assay quality control.

Apolipoprotein E (APOE) genotyping was performed according to established methods [46]. 
TABLE 2: Demographic characteristics of the investigated groups. Data are mean $(\mathrm{SD})$.

\begin{tabular}{lcc}
\hline & AD patients & Controls \\
\hline Number of subjects & 190 & 164 \\
Sex F (\%) & 70 & 68 \\
Education mean (SD) & $9(5.0)$ & $9.3(4.6)$ \\
Age (years) mean (SD) & $74.4(7.9)^{\mathrm{a}}$ & $67.7(11.2)$ \\
MMSE mean (SD) & $18.6(5.8)^{\mathrm{a}}$ & $28.3(1.2)$ \\
APOE $\varepsilon 4$ frequency $(\%)$ & $35^{\mathrm{a}}$ & 13 \\
\hline
\end{tabular}

${ }^{*}$ Correlation is significant at the 0.05 level (2-tailed).

${ }^{a}$ Significantly different between $\mathrm{AD}$ and control group $(P<.001)$.

${ }^{\mathrm{b}}$ Significantly different between $\mathrm{AD}$ and control group $(P<.05)$.

2.2. Statistical Analyses. Demographic and clinical characteristics in our patient and control samples were described either in terms of mean $\pm \mathrm{SD}$ if quantitative, or in terms of proportions.

To calculate the power analysis of our study we considered data reported in general population $(\mathrm{CEPH})[47,48]$ of SNPs allele distribution. As the presence of TG heterozygosis in healthy individuals was about $40 \%$ for c.1216 SNP and that of AG heterozygosis was 52\% for c.2945 SNP [47, 48], we estimated that, with our sample size, the power was $80 \%$ to recognize as significant (at bilateral alpha level of 0.05 ) a higher prevalence in $\mathrm{AD}$ with respect to controls of $12 \%$ (or more) for c. 1216 SNP and of 11\% for c.2945 SNP.

After checking for normality, Student's $t$-tests were used when appropriate to evaluate differences in quantitative variables. The differences in the overall distribution of the alleles among normal and AD chromosomes were evaluated by $\chi^{2}$ test. The association of the allele with the largest positive deviation between the observed and the expected frequency under null hypothesis was represented with a $2 \times 2$ table and tested by means of $\chi^{2}$ test. The relative risk of having $\mathrm{AD}$ was estimated by Odds Ratios (ORs), and corresponding 95\% CIs were also provided. Two-sided $\chi^{2}$ tests were used to verify Hardy-Weinberg equilibrium. Logistic regression analysis with group (cases and controls) as dependent variable and genetic and demographic measures as independent variables allowed identifying the characteristics more able to discriminate the two groups.

Coefficient pairwise Linkage Disequilibrium (LD; D') between ATP 7B SNPs was estimated using Haploview version 4.2 [49].

All analyses were conducted with SPSS software version 16.0 (SPSS Ltd., Surrey, UK). A $P$ value less than .05 was considered significant in all statistical analysis.

\section{Results}

Main demographic and clinical characteristics of the subjects participating to this study were reported in Table 2. AD patients and controls did not differ for sex, but differed in age, mean MMSE score, and APOE $\varepsilon 4$ allele frequency (Table 2). As the age effect was considered a potentially confounding factor, it was taken into account in the statistical analyses. As expected, the mean MMSE score was lower in patients than in controls. Education did not differ between the 2 groups, while the presence of at least one APOE $\varepsilon 4$ allele was more frequent in patients than in controls $(\mathrm{OR}=3.7$; 95\% CI $=2.1-6.5 ; P<.001)$.

The genetic screening for WD mutations in the sole AD cohort by direct sequencing was restricted to exons $2,5,8$, 14 , and 16 of the ATP7B gene in 180 chromosomes, while it was carried out in 360 AD chromosomes and 302 control chromosomes for exon 10 . The study revealed no mutations, but sequence changes corresponding to the c.1216 $\mathrm{T}>\mathrm{G}$ (Ser406Ala) in exon 2 and 2495 A>G (Lys832Arg) in exon 10 SNPs occurred.

The Hardy-Weinberg equilibrium was checked in each group. No statistically significant differences were found.

3.1. C.1216 T>G SNP (Exon 2) in AD and Healthy Controls. Genotype frequencies of c.1216 T $>$ G SNP in our control panel were as follows: TT 30.9\%, TG 49.6\%, and GG $19.5 \%$. In $\mathrm{AD}$ patients they were not different, being $\mathrm{TT} 24.1 \%$, TG 50.6\%, and GG 25.3\% ( $\left.\chi^{2}=2.25, P=.325\right)$. Also allele frequency did not differ between groups (Table 3 ). When we merged data of TG and TT genotype carriers together and compared their pooled frequency versus that of GG genotype in a model of logistic regression analysis taking into account the age effect, we observed a higher frequency of GG in patients than in controls, although the difference was only marginally significant $(\mathrm{OR}=1.773 ; 95 \% \mathrm{CI}=0.947-3.320$; $P=.074$; Table 3 ).

3.2. C.2495 A>G SNP (Exon 10) in AD and Healthy Controls. c.2495 $\mathrm{A}>\mathrm{G}$ genotype frequencies in our control panel were as follows: AA 14.6\%, AG 56.3\%, and GG 29.1\%. In $\mathrm{AD}$ patients they were not different, being $\mathrm{AA} 9.4 \%$, AG 57.1\%, and GG 38.9\%. The overall $\chi^{2}$ indicated that the 2 distributions were not clearly different $\left(\chi^{2}=4.42\right.$, $P=.110$ ), although the linear component (considering the number of $G$ alleles: $0,1,2$ ) suggested there was an association $\left(\chi^{2}=4.441, P=.036\right)$. $\mathrm{G}$ allele frequency was higher in AD than in controls $\left(\chi^{2}=3.8, P=.05\right)$. Furthermore, when we merged data of AG and GG genotype carriers together and compared their pooled frequency versus that of GG genotype, in a model of logistic regression, GG category was significantly more frequent in $\mathrm{AD}$ patients than in controls (Table 4). In particular, GG genotype was carried by 39\% of AD patients versus $29 \%$ of healthy controls and resulted in a significant odds ratio $(\mathrm{OR}=1.741 ; 95 \% \mathrm{CI}=1.060-2.858$; $P=.028)$.

Allele frequency of the 2 SNPs in our cohorts (Tables 3 and 4) resembles those reported in HapMap for European origin populations.

To verify whether c.1216 T>G and c.2495 A>G SNPs were in linkage disequilibrium (LD), we constructed plots for our 2 cohorts and compared them with those reported in HapMap database (http://www.hapmap.org/) for European origin population (Figure 1). The analysis revealed that the 2 ATP7B SNPs were not in high LD in our population, either 
TABLE 3: c.1216 T>G ATP7B (exon 2) SNP allele distribution in AD patients and healthy controls and comparison of GG versus TG + TT.

\begin{tabular}{lccc}
\hline c.1216 T>G ATP7B & AD patients & Controls \\
$($ exon 2) & $(162)$ & $123)$ & $P$ value \\
\hline Allele T frequency n (\%) & $160(49 \%)$ & $137(55.7 \%)$ & $\chi^{2}=2.23 ; \mathrm{df}=1 ;$ \\
Allele G frequency n (\%) & $164(51 \%)$ & $109(44.3 \%)$ & $P=.13$ \\
\hline GG n (\%) & $41(25.3 \%)$ & $24(19.5 \%)$ & $P=.074^{*}$ \\
TG + TT n (\%) & $121(74.7 \%)$ & $99(80.5 \%)$ & \multirow{2}{*}{} \\
\hline
\end{tabular}

Correlation is significant at the .05 level (2-tailed). ${ }^{*}$ The analyses were corrected for the age effect.

TABle 4: c.2495 A>G ATP7B (exon 10) SNP allele distribution in AD patients and healthy controls and comparison between GG versus $\mathrm{AG}+\mathrm{AA}$.

\begin{tabular}{lccc}
\hline $\begin{array}{l}\text { c.2495 A }>\text { G ATP7B } \\
\text { (exon 10) SNP }\end{array}$ & $\begin{array}{c}\text { AD patients } \\
(180)\end{array}$ & Controls $(151)$ & $P$ value \\
\hline Allele A frequency n (\%) & $127(35 \%)$ & $129(43 \%)$ & $\chi^{2}=3.8 ; \mathrm{df}=1 ;$ \\
Allele G frequency n (\%) & $233(65 \%)$ & $173(57 \%)$ & $P=.05$ \\
\hline GG n (\%) & $70(39 \%)$ & $44(29 \%)$ & $P=.028^{*}$ \\
AG + AA n (\%) & $110(61 \%)$ & $107(71 \%)$ & \multirow{2}{*}{} \\
\hline
\end{tabular}

Correlation is significant at the .05 level (2-tailed). ${ }^{*}$ The analyses were corrected for the age effect.

when analysing the subjects' sample separately as an $\mathrm{AD}\left(\mathrm{D}^{\prime}\right.$ $=0.74 ;$ D' confidence bounds-Conf. Bounds-0.60-0.84) and a control $\left(\mathrm{D}^{\prime}\right.$ value $=0.64$; Conf. Bounds 0.5-0.77) cohort or when considering the subjects as a combined population $\left(\mathrm{D}^{\prime}\right.$ value $=0.70$; Conf. Bounds 0.59-0.79). The degree of LD calculated for the Italian Tuscan population (TSI; D' = 90; Conf. Bounds 0.77-0.97) and for the Utah residents with Northern and Western European ancestry from $\mathrm{CEPH}$ collection (CEU; $\left.\mathrm{D}^{\prime}=93 ; 0.85-0.98\right)$, on the basis of data reported in HapMap database, was higher than that we identified (Figure 2).

APOE $\varepsilon 4$ and ATP7B (both c.1216 T $>$ G and c.2495 A $>$ G) SNPs were independent AD risk factors, since there was no difference in the frequency of the ATP7B SNPs between carriers and noncarriers of the APOE $\varepsilon 4$ allele (consistently $P>.2$ ), in addition to when the analysis was restricted to assessment of only the AD population (consistently $P>.2$ ).

\section{Discussion}

We have focused the current investigation on ATP7B WD gene, which is a tight control balance regulator for free copper levels in the body $[42,43,50]$. ATPase $7 \mathrm{~B}$ protein is expressed at high levels in the liver and kidney and at lower levels in the lung, placenta, and brain [50]. It is localized to the trans-Golgi membrane where it maintains intracellular copper concentration by transporting copper from the cytosol across the Golgi lumen. In the Golgi lumen, ATPase $7 \mathrm{~B}$ mediates the incorporation of copper atoms into ceruloplasmin during its biosynthesis [51-53]. Under elevated copper concentrations ATPase 7B undergoes a reversible, copper-mediated translocation from the trans-Golgi to the apical canalicular membrane where it pumps copper directly into the bile [51-56]. In WD, defects of ATPase 7B prevents

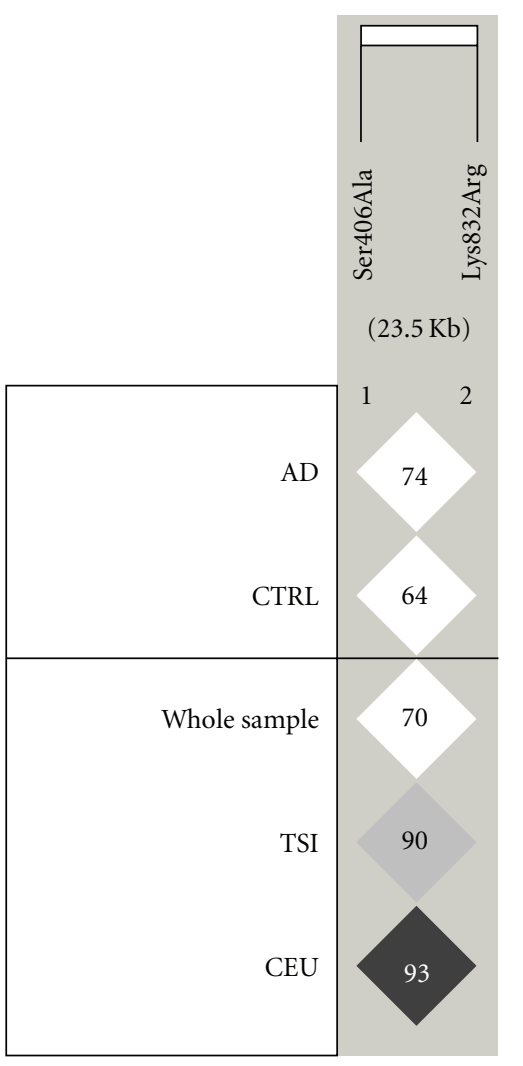

FIgURE 2: Pairwise LDs are shown, calculated between the ATP7B gene SNPs in AD, controls, whole sample and in HapMap European origin populations (CEU: Utah residents with Northern and Western European ancestry from the CEPH collection; TSI: Tuscans in Italy). The top panel depicts the location of the SNPs in the AT7PB gene. The intensity of the box shading is proportional to the strength of the LD ( $\mathrm{D}^{\prime}$ confidence bounds) for the marker pair, which is also indicated as a percentage within each box. 
copper translocation to the secretory pathway as well as the excretion trough the bile, resulting in free copper increased levels and in the secretion of apoceruloplasmin which, being unstable, is rapidly degraded in the blood [54, 57]. In a dedicated study, we have shown that a conspicuous amount of apoceruloplasmin is present in the CSF of AD patients [58]. We have also reported fragmentation of ceruloplasmin, revealed by the presence of low-molecular-weight fragments $(<50 \mathrm{KDa})$ of ceruloplasmin in $\mathrm{AD}$ samples from selected patients with higher-than-normal levels of free copper [59].

The most common Mediterranean WD mutations were reported to lie primary in exons $2,5,8,10,14$, and 16 [47, 48, 60-68]. In particular, the Cys271Stop mutation in exon 2 was reported to account for $19 \%$ of the total mutations in the European and Turkish population [61]. 1708-1 G>C, 1785 delT, and 1823 del3 have been identified in the Italian population (exon 5) [62-65]. The 2299insC mutation in exon 8 was found in Continental Italians [63]. In the same exon lies the Arg 778 Leu mutation, which is the prevalent mutation of the Mongoloid population [60]. The 2464delC in exon 10 was found in Sardinian and the 2533delA in Sardinian, Continental Italian, Turkish, and Albanian populations [62]. His1069Gln in exon 14, which was reported to account for $17.5 \%$ of WD mutations in Mediterraneans, was also found in $20-40 \%$ of the WD cases in different Caucasian population groups [47, 63, 65, 66, 68]. Val1146Met and Ile1148Thr in exon 16 have been identified in Greek population [62-65]. Along with these relatively common mutations, several other very rare mutations in Mediterraneans have been described in the exons object of our pilot investigation [62-65].

The ATP7B gene sequence analysis of exons 2, 5, 8, 14, 16 in $180 \mathrm{AD}$ chromosomes-and 662 chromosomes only for exon 10-did not reveal any other sequence change than c.1216 T>G and c.2495 A>G ATP7B SNPs. As a result we focused our study on these 2 SNPs.

Our main observation is that c.2495 A>G ATP7B SNP as either the $G$ allele frequency or the rate of distribution of the GG genotype is higher in $\mathrm{AD}$ patients than in healthy controls. The c.1216 T>G SNP was also differently distributed between $\mathrm{AD}$ and healthy controls but the significance did not reach the statistical threshold, probably because of the small size of the patient's sample analyzed. However, it has to be noted that the potential role as $\mathrm{AD}$ risk factor of the considered ATP7B SNPs could have been masked by the difference of 7 years between our $\mathrm{AD}$ patients and controls. In the attempt to reduce this potential confounder we took into account an age effect in our statistical analyses. However, the possibility that some controls might convert to $\mathrm{AD}$ while they age another 7 years makes controls and cases more close to each other, and thus our estimate of the statistical association between AD and these SNPs should be considered conservative.

Genotypes and allele distributions for both SNPs found in our panel were coherent with those reported in HapMap for general populations of European origin [47, 48]. While c.1216 $\mathrm{T}>\mathrm{G}$ and c.2495 $\mathrm{A}>\mathrm{G}$ SNPs are in LD in TSI and in CEU samples, in our panel they resulted in a lower LD degree.

Exon 2 encodes for a region containing metal-binding domains in ATPase 7B protein. This region encompasses amino acids 1-481. The genetic change in c.1216 T>G SNP corresponds to a substitution ser 406 ala, within this region. Exon 10 encodes for a region within the ATP binding domain region in the protein which encompasses amino acids 820967. The genetic variation in c.2495 $\mathrm{A}>\mathrm{G}$ corresponds to a lys 832 arg substitution [43] within this region. Thus it could be argued that these amino acids changes can have an a disturbing effect on ATPase7B function in terms of metal binding properties or ATP hydrolysis which can eventually result in copper homeostasis abnormalities.

This study has a number of limitations which include the small size of the sample, 7 years between cases and controls, the restriction of the sequence analysis to a limited number of ATP7B exons, the need for AD selection with possible sampling bias, and surely it needs confirmation in a larger subject population (in progress). Despite these limitations, this pilot investigation opens new routes-genetic rather than biochemical-for the study of free copper deregulation in $\mathrm{AD}$ and strengthens the concept that properly tuning the redistribution of metals via metal complexing or ligand agents, as successfully tested for WD, may positively affect the natural history of AD, at least for the ATP7B c.2495 GG $\mathrm{AD}$ carriers $[1,28,69]$.

\section{Conflict of Interests}

The authors declare no conflict of interests.

\section{Acknowledgments}

This study was partially supported by the following grants: Italian Health Department: "Profilo Biologico e Genetico della Disfunzione dei Metalli nella Malattia di Alzheimer e nel "Mild Cognitive Impairment" [RF 2006 conv.58]; Programma Strategico 2007 conv. PS39; "Ricerca Corrente" grants IRCCS Brescia, Italy, ERA-Net NEURON (JTC 2008 nEUROsyn), AFaR Foundation-Osp. Fatebenefratelli "AAMS 1 gioco sicuro."

\section{References}

[1] A. I. Bush and R. E. Tanzi, "Therapeutics for Alzheimer's disease based on the metal hypothesis," Neurotherapeutics, vol. 5, no. 3, pp. 421-432, 2008.

[2] M. A. Smith, P. L. R. Harris, L. M. Sayre, and G. Perry, "Iron accumulation in Alzheimer disease is a source of redoxgenerated free radicals," Proceedings of the National Academy of Sciences of the United States of America, vol. 94, no. 18, pp. 9866-9868, 1997.

[3] N. Arnal, D. O. Cristalli, M. J.T. de Alaniz, and C. A. Marra, "Clinical utility of copper, ceruloplasmin, and metallothionein plasma determinations in human neurodegenerative patients and their first-degree relatives," Brain Research, vol. 1319, pp. 118-130, 2010. 
[4] R. Agarwal, S. S. Kushwaha, C. B. Tripathi, N. Singh, and N. Chhillar, "Serum copper in Alzheimer's disease and vascular dementia," Indian Journal of Clinical Biochemistry, vol. 23, no. 4, pp. 369-374, 2008.

[5] B. Bocca, G. Forte, F. Petrucci et al., "Monitoring of chemical elements and oxidative damage in patients affected by Alzheimer's disease," Annali dell'Istituto Superiore di Sanita, vol. 41, no. 2, pp. 197-203, 2005.

[6] C. González, T. Martín, J. Cacho et al., "Serum zinc, copper, insulin and lipids in Alzheimer's disease epsilon 4 apolipoprotein E allele carriers," European Journal of Clinical Investigation, vol. 29, no. 7, pp. 637-642, 1999.

[7] S. U. O. Sevym, I. Tamer, O. Doğu, and A. Ozge, "Can serum levels of copper and zinc distinguish Alzheimer's patients from normal subjects?" Journal of Neurological Sciences (Turkish), vol. 24, no. 3, pp. 197-205, 2007.

[8] C. Smorgon, E. Mari, A. R. Atti et al., "Trace elements and cognitive impairment: an elderly cohort study," Archives of Gerontology and Geriatrics. Supplement, no. 9, pp. 393-402, 2004.

[9] R. Squitti, G. Barbati, L. Rossi et al., "Excess of nonceruloplasmin serum copper in AD correlates with MMSE, CSF $\beta$ amyloid, and h-tau," Neurology, vol. 67, no. 1, pp. 76-82, 2006.

[10] R. Squitti, F. Bressi, P. Pasqualetti et al., "Longitudinal prognostic value of serum "free" copper in patients with Alzheimer disease," Neurology, vol. 72, no. 1, pp. 50-55, 2009.

[11] R. Squitti, P. Pasqualetti, E. Cassetta et al., "Elevation of serum copper levels discriminates Alzheimer's disease from vascular dementia," Neurology, vol. 60, no. 12, pp. 2013-2014, 2003.

[12] R. Squitti, M. Ventriglia, G. Barbati et al., "Free' copper in serum of Alzheimer's disease patients correlates with markers of liver function," Journal of Neural Transmission, vol. 114, no. 12, pp. 1589-1594, 2007.

[13] F. Zappasodi, C. Salustri, C. Babiloni et al., "An observational study on the influence of the APOE- $\varepsilon 4$ allele on the correlation between 'free' copper toxicosis and EEG activity in Alzheimer disease," Brain Research, vol. 1215, no. C, pp. 183-189, 2008.

[14] H. Basun, L. G. Forssell, L. Wetterberg, and B. Winblad, "Metals and trace elements in plasma and cerebrospinal fluid in normal ageing and Alzheimer's disease," Journal of Neural Transmission, vol. 3, no. 4, pp. 231-258, 1991.

[15] L. Baum, I. H. S. Chan, S. K. K. Cheung et al., "Serum zinc is decreased in Alzheimer's disease and serum arsenic correlates positively with cognitive ability," BioMetals, vol. 23, no. 1, pp. 173-179, 2010.

[16] L. Gerhardsson, T. Lundh, L. Minthon, and E. Londos, "Metal concentrations in plasma and cerebrospinal fluid in patients with Alzheimer's disease," Dementia and Geriatric Cognitive Disorders, vol. 25, no. 6, pp. 508-515, 2008.

[17] C. Jeandel, M. B. Nicolas, F. Dubois, F. Nabet-Belleville, F. Penin, and G. Cuny, "Lipid peroxidation and free radical scavengers in Alzheimer's disease," Gerontology, vol. 35, no. 56, pp. 275-282, 1989.

[18] E. Kapaki, J. Segditsa, C. Zournas, D. Xenos, and C. Papageorgiou, "Determination of cerebrospinal fluid and serum lead levels in patients with amyotrophic lateral sclerosis and other neurological diseases," Experientia, vol. 45, no. 11-12, pp. 1108-1110, 1989.

[19] G. Mattiello, M. Gerotto, M. Favarato et al., "Plasma microelement analysis from Alzheimer's and multi-infartual dementia patients," Alzheimer's Diseases: Advances in Clinical and Basic Research, 1993.
[20] J. A. Molina, F. J. Jiménez-Jiménez, M. V. Aguilar et al., "Cerebrospinal fluid levels of transition metals in patients with Alzheimer's disease," Journal of Neural Transmission, vol. 105, no. 4-5, pp. 479-488, 1998.

[21] R. Ozcankaya and N. Delibas, "Malondialdehyde, superoxide dismutase, melatonin, iron, copper, and zinc blood concentrations in patients with Alzheimer disease: cross-sectional study," Croatian Medical Journal, vol. 43, no. 1, pp. 28-32, 2002.

[22] B. Sedighi, M. A. Shafa, and M. Shariati, "A study of serum copper and ceruloplasmin in Alzheimer's disease in Kerman, Iran," Neurology Asia, vol. 11, pp. 107-109, 2006.

[23] J. Snaedal, J. Kristinsson, S. Gunnarsdóttir et al., "Copper, ceruloplasmin and superoxide dismutase in patients with Alzheimer's disease. A case-control study," Dementia and Geriatric Cognitive Disorders, vol. 9, no. 5, pp. 239-242, 1998.

[24] H. Vural, H. Demirin, Y. Kara, I. Eren, and N. Delibas, "Alterations of plasma magnesium, copper, zinc, iron and selenium concentrations and some related erythrocyte antioxidant enzyme activities in patients with Alzheimer's disease," Journal of Trace Elements in Medicine and Biology, vol. 24, no. 3, pp. 169-173, 2010.

[25] G. J. Brewer, S. H. Kanzer, E. A. Zimmerman et al., "Copper and ceruloplasmin abnormalities in Alzheimer's disease," American Journal of Alzheimer's Disease and Other Dementias, vol. 25, no. 6, pp. 490-497, 2010.

[26] S. Bucossi, M. Ventriglia, V. Panetta et al., "Copper in Alzheimer's disease: a meta-analysis of serum, plasma, and cerebrospinal fluid studies," Journal of Alzheimer's Disease, vol. 24, no. 1, pp. 175-185, 2011.

[27] J. M. Walshe, "Wilson's disease: the importance of measuring serum caeruloplasmin non-immunologically," Annals of Clinical Biochemistry, vol. 40, part 2, pp. 115-121, 2003.

[28] R. Squitti and C. Salustri, "Agents complexing copper as a therapeutic strategy for the treatment of Alzheimer's disease," Current Alzheimer Research, vol. 6, no. 6, pp. 476-487, 2009.

[29] J. S. Althaus, J. F. Quinn, J. A. Kaye et al., "Free copper measured directly in serum using a novel device is elevated in Alzheimer's disease," Investigative Ophthalmology \& Visual Science, vol. 49, E-abstract, p. 5218, 2008.

[30] T. U. Hoogenraad, "Measuring hypercupremia in blood of patients with Alzheimer's disease is logical, but the utility of measuring free-copper has to be proven," in Neurologie, C. J. M. Frijns, L. J. Kappelle, C. J. M. Klijn, and J. H. J. Wokke, Eds., pp. 111-112, Utrechts: Tijdschrift voor, 2007.

[31] M. C. Linder, P. A. Houle, E. Isaacs et al., "Copper regulation of ceruloplasmin in copper-deficient rats," Enzyme, vol. 24, no. 1, pp. 23-35, 1979.

[32] J. G. Chutkow, "Evidence for uptake of nonceruloplasminic copper in the brain: effect of ionic copper and amino acids," Proceedings of the Society for Experimental Biology and Medicine, vol. 158, no. 1, pp. 113-116, 1978.

[33] D. E. Hartter and A. Barnea, "Brain tissue accumulates copper by two ligand-dependent saturable processes. A high affinity, low capacity and a low affinity, high capacity process," Journal of Biological Chemistry, vol. 263, no. 2, pp. 799-805, 1988.

[34] B. S. Choi and W. Zheng, "Copper transport to the brain by the blood-brain barrier and blood-CSF barrier," Brain Research, vol. 1248, pp. 14-21, 2009.

[35] T. U. Hoogenraad, C. J. A. Van Den Hamer, R. Koevoet, and E. G. W. De Ruyter Korver, "Oral zinc in Wilson's disease," Lancet, vol. 2, no. 8102, p. 1262, 1978. 
[36] I. H. Scheinberg and I. Sternlieb, "Wilson's disease," in Problems in Internal Medicine, L. H. Smith, Ed., Saunders, Philadelphia, Pa, USA, 1984.

[37] M. Siotto, S. Bucossi, and R. Squitti, "Copper status abnormalities and how to measure them in neurodegenerative disorders," Recent Patents in CNS Drug Discovery, vol. 5, no. 3, pp. 182-194, 2010.

[38] R. Squitti, D. Lupoi, P. Pasqualetti et al., "Elevation of serum copper levels in Alzheimer's disease," Neurology, vol. 59, no. 8, pp. 1153-1161, 2002.

[39] C. Babiloni, R. Squitti, C. Del Percio et al., "Free copper and resting temporal EEG rhythms correlate across healthy, mild cognitive impairment, and Alzheimer's disease subjects," Clinical Neurophysiology, vol. 118, no. 6, pp. 1244-1260, 2007.

[40] R. Squitti, P. Pasqualetti, G. Dal Forno et al., "Excess of serum copper not related to ceruloplasmin in Alzheimer disease," Neurology, vol. 64, no. 6, pp. 1040-1046, 2005.

[41] M. F. Folstein, S. E. Folstein, and P. R. McHugh, “"Mini mental state". A practical method for grading the cognitive state of patients for the clinician," Journal of Psychiatric Research, vol. 12, no. 3, pp. 189-198, 1975.

[42] K. Petrukhin, S. G. Fischer, M. Pirastu et al., "Mapping, cloning and genetic characterization of the region containing the Wilson disease gene," Nature Genetics, vol. 5, no. 4, pp. 338-343, 1993.

[43] R. E. Tanzi, K. Petrukhin, I. Chernov et al., "The Wilson disease gene is a copper transporting ATPase with homology to the Menkes disease gene," Nature Genetics, vol. 5, no. 4, pp. 344-350, 1993.

[44] B. Dubois, H. H. Feldman, C. Jacova et al., "Research criteria for the diagnosis of Alzheimer's disease: revising the NINCDSADRDA criteria," Lancet Neurology, vol. 6, no. 8, pp. 734-746, 2007.

[45] G. McKhann, D. Drachman, M. Folstein et al., "Clinical diagnosis of Alzheimer's disease: report of the NINCDS-ADRDA work group under the auspices of Department of Health and Human Services Task Force on Alzheimer's disease," Neurology, vol. 34, no. 7, pp. 939-944, 1984.

[46] J. E. Hixson and D. T. Vernier, "Restriction isotyping of human apolipoprotein $\mathrm{E}$ by gene amplification and cleavage with HhaI," Journal of Lipid Research, vol. 31, no. 3, pp. 545-548, 1990.

[47] A. Gupta, D. Aikath, R. Neogi et al., "Molecular pathogenesis of Wilson disease: haplotype analysis, detection of prevalent mutations and genotype-phenotype correlation in Indian patients," Human Genetics, vol. 118, no. 1, pp. 49-57, 2005.

[48] A. Gupta, M. Maulik, P. Nasipuri et al., "Molecular diagnosis of Wilson disease using prevalent mutations and informative single-nucleotide polymorphism markers," Clinical Chemistry, vol. 53, no. 9, pp. 1601-1608, 2007.

[49] J. C. Barrett, B. Fry, J. Maller, and M. J. Daly, "Haploview: analysis and visualization of LD and haplotype maps," Bioinformatics, vol. 21, no. 2, pp. 263-265, 2005.

[50] P. C. Bull, G. R. Thomas, J. M. Rommens, J. R. Forbes, and D. W. Cox, "The Wilson disease gene is a putative copper transporting P-type ATPase similar to the Menkes gene," Nature Genetics, vol. 5, no. 4, pp. 327-337, 1993.

[51] M. DiDonato, S. Narindrasorasak, J. R. Forbes, D. W. Cox, and B. Sarkar, "Expression, purification, and metal binding properties of the N-terminal domain from the Wilson disease putative copper-transporting ATPase (ATP7B)," Journal of Biological Chemistry, vol. 272, no. 52, pp. 33279-33282, 1997.
[52] M. DiDonato and B. Sarkar, "Copper transport and its alterations in Menkes and Wilson diseases," Biochimica et Biophysica Acta, vol. 1360, no. 1, pp. 3-16, 1997.

[53] M. Didonato, J. Zhang, L. Que Jr., and B. Sarkar, "Zinc binding to the NH-terminal domain of the Wilson disease coppertransporting ATPase. Implications for in vivo metal ionmediated regulation of ATPase activity," Journal of Biological Chemistry, vol. 277, no. 16, pp. 13409-13414, 2002.

[54] K. Terada, M. L. Schilsky, N. Miura, and T. Sugiyama, "ATP7B (WND) protein," International Journal of Biochemistry and Cell Biology, vol. 30, no. 10, pp. 1063-1067, 1998.

[55] H. Roelofsen, H. Wolters, M. J. A. Van Luyn, N. Miura, F. Kuipers, and R. J. Vonk, "Copper-induced apical trafficking of ATP7B in polarized hepatoma cells provides a mechanism for biliary copper excretion," Gastroenterology, vol. 119, no. 3, pp. 782-793, 2000.

[56] M. Schaefer and J. D. Gitlin, "Genetic disorders of membrane transport IV. Wilson's disease and Menkes disease," American Journal of Physiology, vol. 276, no. 2, part 1, pp. G311-G314, 1999.

[57] P. Bielli and L. Calabrese, "Structure to function relationships in ceruloplasmin: a 'moonlighting' protein," Cellular and Molecular Life Sciences, vol. 59, no. 9, pp. 1413-1427, 2002.

[58] C. R. Capo, M. Arciello, R. Squitti et al., "Features of ceruloplasmin in the cerebrospinal fluid of Alzheimer's disease patients," BioMetals, vol. 21, no. 3, pp. 367-372, 2008.

[59] R. Squitti, C. C. Quattrocchi, C. Salustri, and P. M. Rossini, "Ceruloplasmin fragmentation is implicated in 'free' copper deregulation of Alzheimer's disease," Prion, vol. 2, no. 1, pp. 23-27, 2008.

[60] L. M. Chuang, H. P. Wu, M. H. Jang et al., "High frequency of two mutations in codon 778 in exon 8 of the ATP7B gene in Taiwanese families with Wilson disease," Journal of Medical Genetics, vol. 33, no. 6, pp. 521-523, 1996.

[61] D. Curtis, M. Durkie, P. Balac et al., "A study of Wilson disease mutations in Britain," Human Mutation, vol. 14, no. 4, pp. 304-311, 1999.

[62] A. Figus, A. Angius, G. Loudianos et al., "Molecular pathology and haplotype analysis of Wilson disease in Mediterranean populations," American Journal of Human Genetics, vol. 57, no. 6, pp. 1318-1324, 1995.

[63] G. Loudianos, V. Dessi, M. Lovicu et al., "Mutation analysis in patients of Mediterranean descent with Wilson disease: identification of 19 novel mutations," Journal of Medical Genetics, vol. 36, no. 11, pp. 833-836, 1999.

[64] G. Loudianos, V. Dessì, M. Lovicu et al., "Haplotype and mutation analysis in Greek patients with Wilson disease," European Journal of Human Genetics, vol. 6, no. 5, pp. 487491, 1998.

[65] G. Loudianos, V. Dessì, M. Lovicu et al., "Further delineation of the molecular pathology of Wilson disease in the Mediterranean population," Human Mutation, vol. 12, no. 2, pp. 8994, 1998

[66] A. B. Shah, I. Chernov, H. T. Zhang et al., "Identification and analysis of mutations in the Wilson disease gene (ATP7B): population frequencies, genotype-phenotype correlation, and functional analyses," American Journal of Human Genetics, vol. 61, no. 2, pp. 317-328, 1997.

[67] G. R. Thomas, J. R. Forbes, E. A. Roberts, J. M. Walshe, and D. W. Cox, "The Wilson disease gene: spectrum of mutations and their consequences," Nature Genetics, vol. 9, no. 2, pp. 210217, 1995 . 
[68] G. R. Thomas, E. A. Roberts, J. N. Walshe, and D. W. Cox, "Haplotypes and mutations in Wilson disease," American Journal of Human Genetics, vol. 56, no. 6, pp. 1315-1319, 1995.

[69] R. Squitti and G. Zito, "Anti-copper therapies in Alzheimer's disease: new concepts," Recent Patents on CNS Drug Discovery, vol. 4, no. 3, pp. 209-219, 2009. 


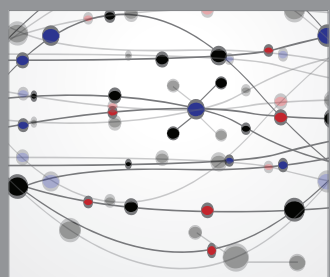

The Scientific World Journal
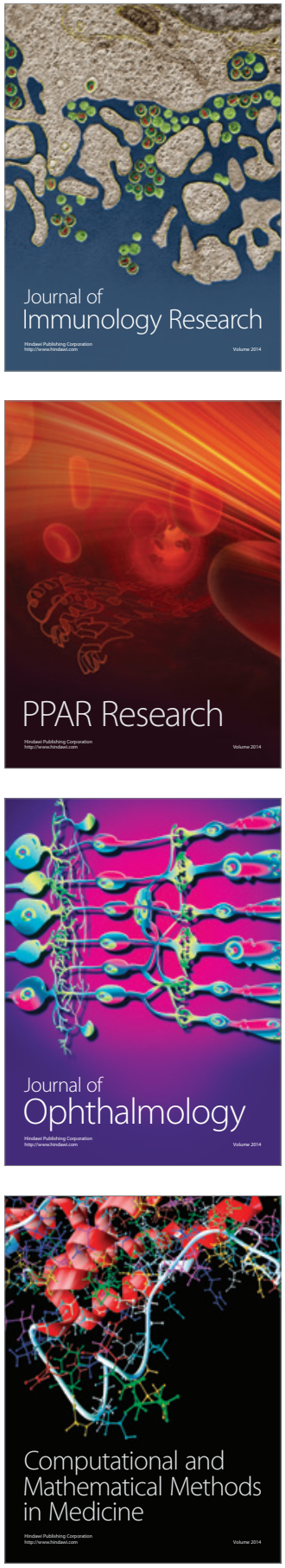

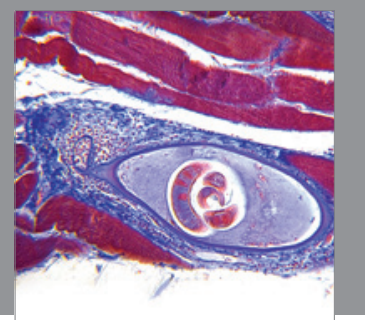

Gastroenterology

Research and Practice
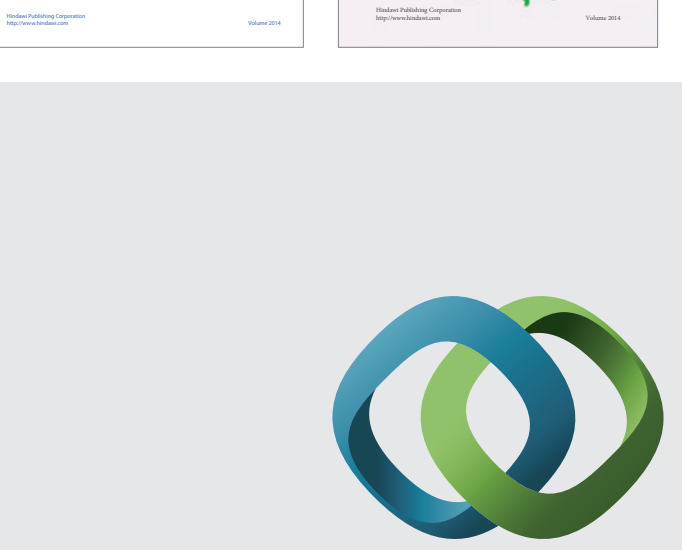

\section{Hindawi}

Submit your manuscripts at

http://www.hindawi.com
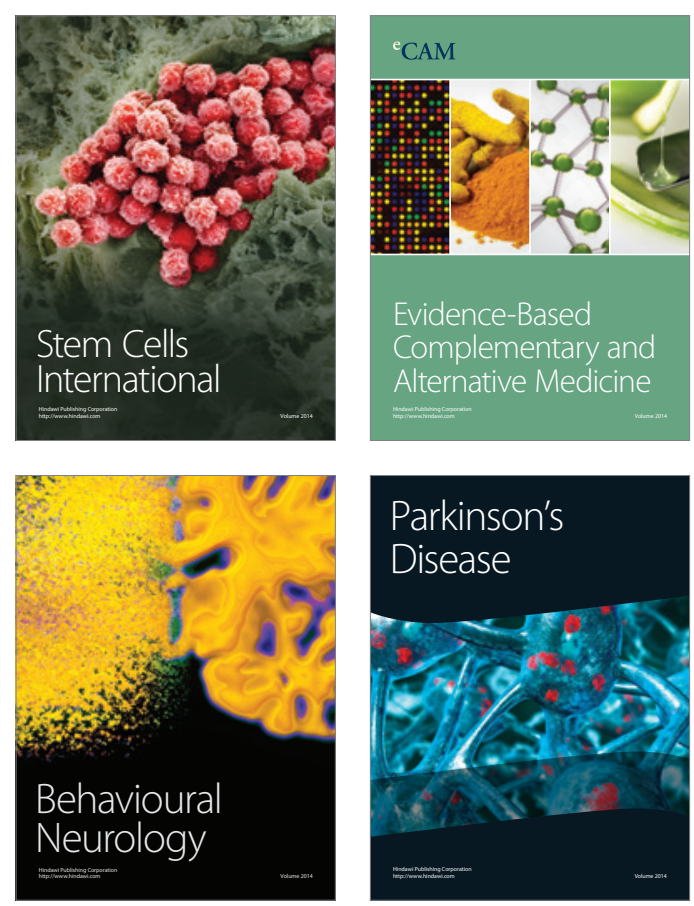

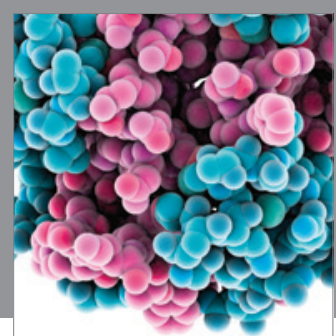

Journal of
Diabetes Research

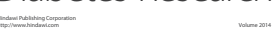

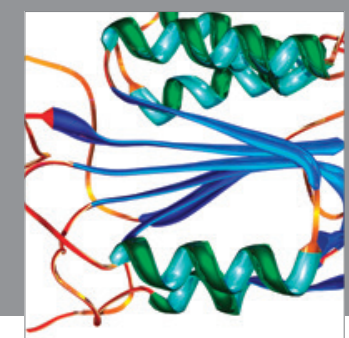

Disease Markers
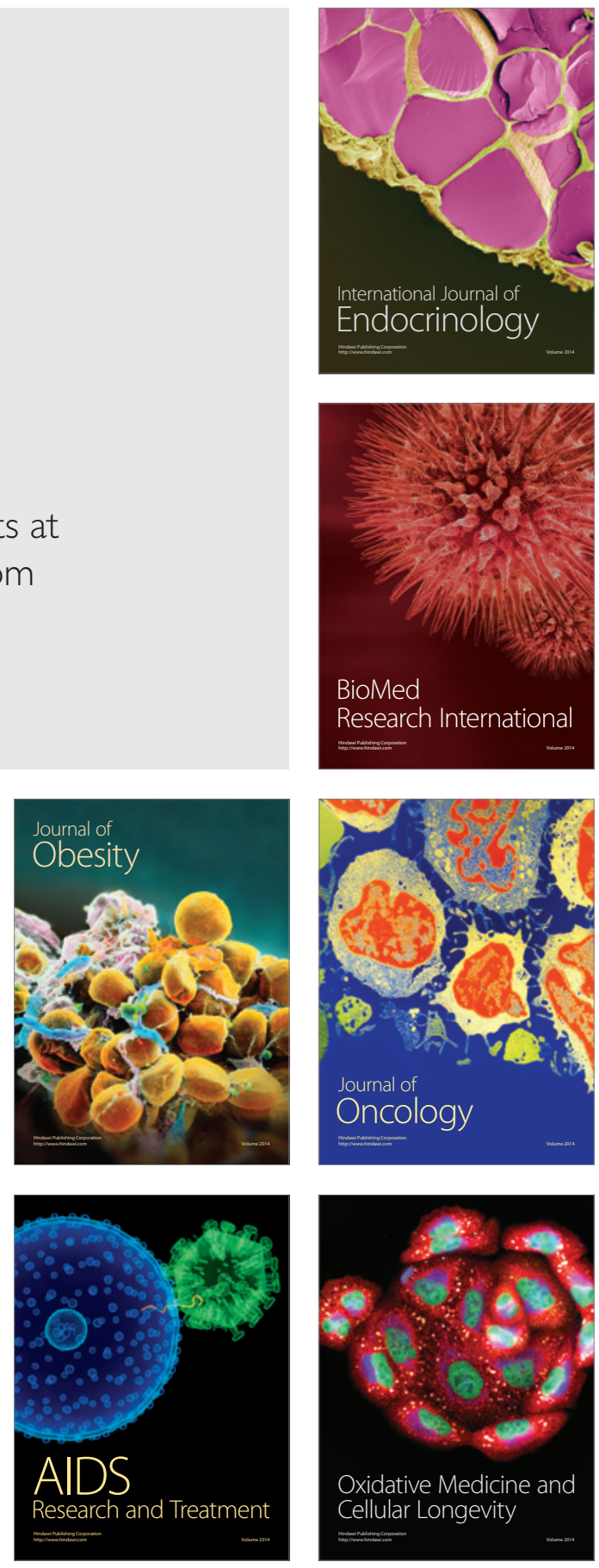